\title{
Efeito alelopático de Libidibia ferrea Mart. sobre o vigor das sementes de feijão-caupi
}

\section{Allelopathic effect of Libidibia ferrea Mart. on the vigor of cowpea seeds}

\author{
Rafael Mateus Alves ${ }^{1 *}$; Monalisa Alves Diniz da Silva ${ }^{2}$ Joyce Naiara da Silva ${ }^{3}$ : Rosemeire Santos \\ Costa $^{4}$; Bruna Kaline de Lima Santos ${ }^{5}$; Edjane da Silva Lima ${ }^{6}$
}

${ }^{1}$ Graduação em Agronomia, Universidade Federal Rural de Pernambuco, Serra Talhada, Fone: (87) 99637-6229, E-mail: rafaelalvesmateus@ gmail.com; ${ }^{2}$ Professora Doutora Associado I, Universidade Federal Rural de Pernambuco, Serra Talhada, E-mail: monallyysa@yahoo.com.br; ${ }^{3}$ Mestrado em Agronomia, Universidade Federal da Paraíba, Areia, E-mail: joicenaiara@ hotmail.com; ${ }^{4}$ Graduação em Agronomia, Universidade Federal Rural de Pernambuco, Serra Talhada, E-mail: rosee meire123@hotmail.com; ${ }^{5}$ Graduação em Agronomia, Universidade Federal Rural de Pernambuco, Serra Talhada, E-mail: santoskbruna@gmail.com; ${ }^{6}$ Graduação em Agronomia, Universidade Federal Rural de Pernambuco, Serra Talhada, E-mail: edalima2015@bol.com.br.

\section{N O T A \\ C I E N T Í F I C A}

Recebido: 14/09/2018

Aprovado: 14/06/2019

\section{Palavras-chave: \\ Agrofloresta \\ Vigna unguiculata \\ Caatinga}

\section{R E S U M O}

O feijão-caupi é uma das principais culturas de importância para a região Nordeste, sendo cultivada em áreas da Caatinga, considerando isso é necessário o estudo da interação entre culturas agrícolas e espécies florestais nesse Bioma. Logo, o presente trabalho teve como objetivo avaliar uma possível influência alelopática de folhas secas em processo de decomposição de Libidibia ferrea Mart. sobre o desenvolvimento de plântulas de feijãocaupi, cv. Canapu. As folhas da espécie florestal foram coletadas no horário da manhã, e secas à $40^{\circ} \mathrm{C}$, durante 24 horas em estufa, em seguida foram manualmente fragmentadas e adicionadas em areia formando o substrato, adotou-se as seguinte proporções de folhas secas e areia: $1: 0$ (controle); 1:1/2; 1:1 e 1:2(v:v). Os substratos ficaram decompondo por 15; 30; 45 e 60 dias, o tratamento controle sem decomposição, assim subsequentemente realizou-se a semeadura das sementes de feijão-caupi. Foi avaliado o comprimento da parte aérea e comprimento da raiz, massa seca da parte aérea, do sistema radicular e total de plântulas normais. Foi utilizado o delineamento inteiramente casualizado em esquema fatorial $4 \times 5$ (proporções de areia: folhas secas $\mathrm{x}$ períodos de decomposição). O período de 30 dias de decomposição ocasiona uma redução no comprimento da parte aérea, na massa seca da parte aérea, do sistema radicular e total das plântulas, o aumento das proporções de folhas secas de pau ferro afeta a massa seca da parte aérea e total de plântulas. Diante disso, o cultivo de feijão-caupi, cv. Canapu, e pau ferro em um sistema agroflorestal não é viável.

\section{A B S T R A C T}

The cowpea is one of the main crops of importance for the Northeast region, being cultivated in areas of the Caatinga, considering that it is necessary to study the interaction between agricultural crops and forest species in this biome. Therefore, the present study aimed to evaluate a possible allelopathic influence of dried leaves in the decomposition process of Libidibia ferrea Mart. on the development of caupi bean seedlings, cv. Canapu. The leaves of the forest species were collected in the morning and dried at $40{ }^{\circ} \mathrm{C}$ for 24 hours in the greenhouse, then were manually fragmented and added to sand forming the substrate, the following proportions of dry leaves and sand were adopted: 1:0 (control); $1: 1 / 2 ; 1: 1$ and 1:2 (v:v). The substrates were decomposed for 15, 30, 45 and 60 days, the control treatment without decomposition, so subsequently the seeds of cowpea were sown. The seedling height and root length, dry mass of the aerial part of the root system and total normal seedlings were evaluated. The entirely randomized $4 \times 5$ factor scheme was used (sand proportions: dry leaves $\mathrm{x}$ periods of decomposition). The period of 30 days of decomposition causes a reduction in the length of the aerial part, in the dry mass of the aerial part, in the root system and in the total of the seedlings, the increase in the proportions of dry ironwood leaves affects the dry mass of the aerial part and total of the seedlings. Therefore, the cultivation of caupi beans, cv. Canapu, and ironwood in an agroforestry system is not feasible.

\section{Revista Verde \\ ISSN 1981-8203 \\ Pombal, Paraíba, Brasil}

v. 14, n.3, jul.-set, p.476-479, 2019

doi: $10.18378 /$ rvads.v14i3.5974 


\section{INTRODUÇÃO}

O bioma Caatinga estende-se por praticamente toda a região Nordeste, ocupando uma área de $844.453 \mathrm{~km}^{2}$, correspondendo a cerca de $11 \%$ do território nacional, distribuído pelos estados do Ceará, Rio Grande do Norte, Paraíba, Pernambuco, Piauí, Alagoas, Sergipe, Bahia e o norte de Minas Gerais (MMA, 2018). A desertificação e a expansão dos processos erosivos são alguns dos principais efeitos na Caatinga (SOUZA et al., 2015).

O Libidibia ferrea Mart. ex Tul. L.P. Queiroz, espécie arbórea da Caatinga, pertencente à família Fabaceae (Leguminosae), árvore conhecida popularmente como pau ferro, jucá, ibirá-obi e imirá-ita, sendo uma espécie de porte arbóreo, chegando a atingir de 10 a $15 \mathrm{~m}$ de altura, com tronco liso, escuro e com manchas acinzentadas, suas vagens são bastante duras com coloração marrom escura, grande variação em tamanho e quantidade de sementes (LORENZI, 2008a). A espécie é endêmica do Brasil, típica da Caatinga do Nordeste (LEWIS, 2015), podendo ser utilizada para diversos fins como construção civil, fitoterapia, ornamental, forrageiro e destinada à recuperação de áreas degradadas (LORENZI, 2008b).

O feijão-de-corda (Vigna unguiculata (L.) Walp.) destaca-se como a principal cultura de subsistência das regiões Norte e Nordeste do Brasil, representando cerca de $90 \%$ da área cultivada (MATOS FILHO et al., 2009). Vale salientar que esta espécie é uma das mais importantes fontes alimentar das regiões tropicais e subtropicais (SANTOS et al., 2014). Apresentando características agronômicas adaptadas ao cultivo nessas regiões, como a tolerância às condições edafoclimáticas locais (VIEIRA et al., 2010).

Diversas espécies florestais nativas presentes na região Nordeste têm potencial para ser exploradas de forma sustentável através de um sistema agroflorestal, porém é necessário o conhecimento de uma possível inibição da germinação e no estabelecimento de plântulas das espécies cultivadas. Por isto, a alelopatia tem recebido cada vez mais atenção dentro dos estudos biológicos (NEGI et al., 2016). Existe uma grande diversidade de compostos, conhecidos como compostos secundários, que são liberados pelos vegetais no ambiente e visam atrair, repelir, nutrir ou promover toxicidade no desenvolvimento e estabilização de outras plantas, contudo, as interferências proporcionadas por estas substâncias podem ter efeitos benéficos ou maléficos (CHOU, 1999).

É evidente a relevância do conhecimento da atividade alelopática entre as espécies, já que possibilita o conhecimento das relações entre as espécies vegetais, e assim em manejos que possam ser adotadas na agricultura, como na adoção de agroflorestas (MALHEIROS et al., 2014).

É de suma importância a conservação das espécies da Caatinga, sendo fundamental a verificação do potencial alelopático das espécies vegetais presentes nesse Bioma, associadas ao cultivo de espécies agrícolas. Diante do exposto, esse trabalho teve como objetivo avaliar o efeito alelopático de folhas secas em vários períodos de decomposição de Libidibia ferrea Mart sobre o desenvolvimento inicial de plântulas de feijão-caupi cv. Canapu.

\section{MATERIAL E MÉTODOS}

O trabalho foi realizado na Universidade Federal Rural de Pernambuco, Unidade Acadêmica de Serra Talhada. Para a preparação do substrato foi utilizada folhas secas de pau ferro (Libidibia ferrea Mart.), enquanto a espécie cultivada para avaliar o efeito alelopático foi o feijão-caupi (Vigna unguiculata), cv. Canapu.

Foi utilizado o delineamento inteiramente casualizado no esquema fatorial $4 \times 5$ (proporções de areia: folhas secas $\mathrm{x}$ períodos de decomposição).

A coleta das folhas de pau ferro foi realizada em setembro de 2017, no município de Serra Talhada - PE. Para a secagem das mesmas foi utilizada uma estufa a $40{ }^{\circ} \mathrm{C}$, durante 24 horas, em seguida as folhas foram acondicionadas em sacos de papel kraft em temperatura ambiente até a instalação do experimento. As folhas secas foram fragmentadas manualmente e adicionadas a areia, previamente esterilizada a $200{ }^{\circ} \mathrm{C}$ por 4 horas, de acordo com as seguintes proporções: 1:0 (controle); 1:1/2; 1:1 e 1:2 (v:v). As folhas de cada mistura permaneceram em período de decomposição de $0 ; 15 ; 30 ; 45$ e 60 dias, na sequência, a semeadura das sementes de feijão-caupi foi realizada em bandejas de isopor com 128 células, sendo semeadas cinco repetições de 20 sementes. A irrigação foi realizada diariamente utilizando água potável.

No $10^{\circ}$ dia após a semeadura avaliou-se o comprimento da parte aérea (CPA) e comprimento do sistema radicular (CSR) com auxílio de uma régua graduada em milímetros e os resultados expressos em centímetros. Posteriormente as plântulas da avaliação anterior foram separadas em parte aérea e raiz colocadas em sacos de papel kraft, separadas por repetição, previamente identificadas e secadas em estufa regulada a $80^{\circ} \mathrm{C}$ por 24 horas conforme recomendações de Nakagawa (1999), decorrido esse período, as amostras foram pesadas em balança analítica com precisão de 0,001 g. A massa seca total (MST) foi determinada pelo somatório da massa seca da parte aérea (MSPA) e massa seca do sistema radicular (MSSR), sendo todos os resultados expressos em gramas.

Os dados obtidos foram submetidos à análise de variância pelo teste $\mathrm{F}$, e as médias foram transformadas para $\sqrt{\mathrm{x}}$ e comparadas pelo teste de Tukey a $5 \%$ de probabilidade, utilizando-se o software estatístico SISVAR (FERREIRA, 2011). Os gráficos foram elaborados com o programa SIGMA PLOT 10.0

\section{RESULTADOS E DISCUSSÃO}

De acordo com a análise da variância, observa-se que não houve interação significativa $(p<0,05)$ para os períodos de decomposição e as proporções de areia e folhas secas da espécie nativa pau ferro (Libidibia ferrea Mart.). Para as variáveis comprimento da parte aérea (CPA) e massa seca do sistema radicular (MSSR) ouve efeito significativo apenas para os períodos de decomposição. As variáveis comprimento do sistema radicular (CSR), massa seca da parte aérea (MSPA), massa seca total (MST) apresentaram diferença significativa para os diferentes períodos de decomposição e proporções de folhas secas de pau ferro.

Os diferentes períodos de decomposição, proporcionaram diferenças no comprimento da parte aérea 
das plântulas de feijão-caupi, cv. Canapu (Figura 1), sendo que os períodos de decomposição de 30,45 e 60 dias de decomposição proporcionaram uma redução no comprimento da parte aérea. De acordo com Ferreira e Borghetti (2004) o crescimento da plântula é mais sensível aos aleloquímicos do que a germinação, pois o modo de ação direto dessas substâncias atua a partir da ligação nas membranas da planta receptora ou da penetração nas células, provocando interferência no metabolismo.

Figura 1. Efeitos dos períodos de decomposição de folhas secas de Libidibia ferrea Mart., sobre o desenvolvimento de plântulas de feijão-caupi (Vigna unguiculata L.), cv. Canapu. Legenda: CPA - Comprimento da parte aérea e CSR comprimento do sistema radicular. Médias seguidas de mesma letra, em cada teste, não diferem estatisticamente entre si, pelo teste de Tukey a $5 \%$.

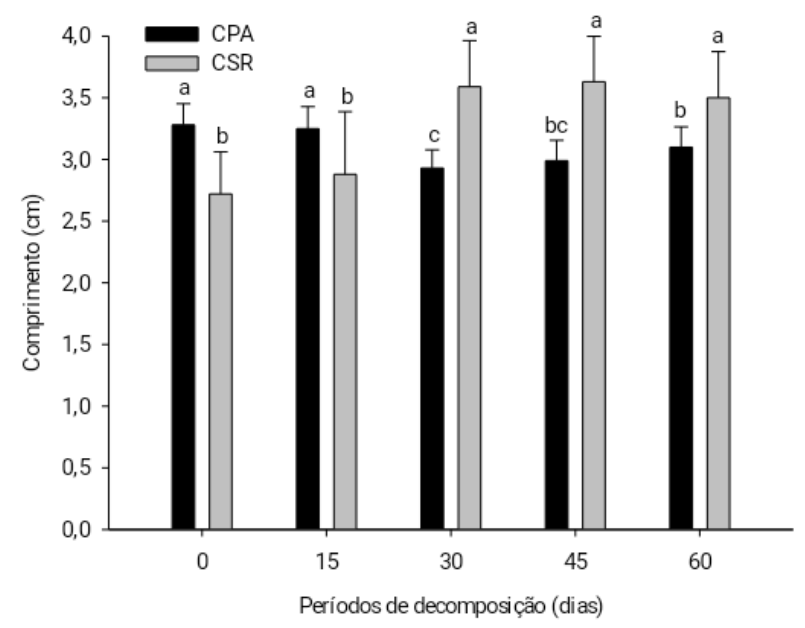

Estudando o efeito de folhas secas de Spondias tuberosa sobre plântulas de feijão-caupi, cv. Canapu, Silva et al. (2017) verificaram a redução no comprimento da parte aérea das plântulas, enquanto o sistema radicular mostrou-se menos sensível, concluindo que o cultivo de feijão-caupi como parte integrante de um sistema agroflorestal em que exista o umbuzeiro, não é recomendado.

Para os valores obtidos para o comprimento do sistema radicular nos diferentes períodos de decomposição, observase que a partir do período de 30 dias de decomposição as folhas secas de pau ferro proporcionaram um incremento no comprimento do sistema radicular, essa observação pode estar relacionada a uma liberação de nutrientes pelas folhas à medida que eram decompostas, dessa forma, a decomposição da serapilheira contribui na fertilização direta do solo (ZHENG et al., 2006).

Com relação aos diferentes períodos de decomposição para as variáveis massa seca da parte aérea (MSPA), massa seca do sistema radicular (MSSR) e massa seca total (MST) o comportamento foi semelhante, sendo que o período de decomposição de 30 dias, ocasionou em uma redução das variáveis estudadas (Figura 2) em relação à ausência de decomposição (0 dias) e 60 dias de decomposição.

Jandová et al. (2015) observaram que os compostos alelopáticos podem interferir significativamente nas variáveis analisadas, podendo sofrer variações em função da concentração estudada.
Figura 2. Efeitos dos períodos de decomposição de folhas secas de Libidibia ferrea Mart., sobre a massa seca de plântulas de feijão-caupi (Vigna unguiculata L.), cv. Canapu. Legenda: MSPA - Massa seca da parte aérea; MSSR - Massa seca do sistema radicular e MST - Massa seca total. Médias seguidas de mesma letra, em cada teste, não diferem estatisticamente entre si, pelo teste de Tukey a $5 \%$.

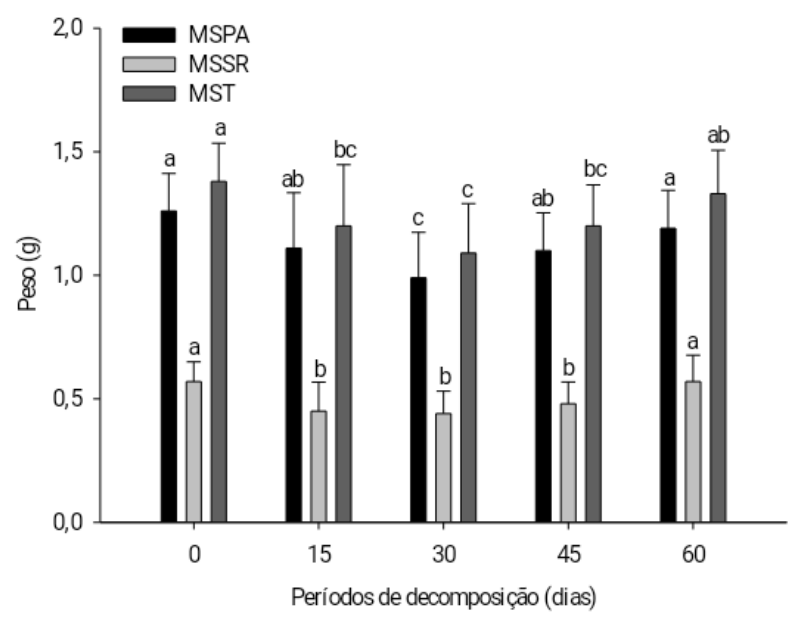

Quanto as diferentes proporções de areia e folhas secas, para as variáveis CPA e MSSR não observou diferença significativa, já para as variáveis MSPA e MST a proporção 1:2 causou redução no acúmulo de massa seca da parte aérea e massa seca total em relação ao uso exclusivo de areia, não diferindo das demais proporções. Estes resultados podem ser em função do substrato utilizados no estudo.

Oliveira et al. (2012) trabalhando com o extrato de folhas, cascas e vagens maduras de Caesalpinia ferrea Mart. sobre a germinação e crescimento inicial de plântulas de alface, verificaram a ocorrência de atividade alelopática, com o aparecimento de plântulas anormais e redução do comprimento da parte aérea e da raiz.

O comprimento do sistema radicular teve um incremento com a utilização das diferentes proporções, quando se comparado com à proporção que era composta apenas por areia (1:0). Segundo Cruz et al. (2000) averiguaram que o preparo, o modo de aplicação e a concentração utilizada são elementos determinantes na obtenção dos resultados, visto que os compostos presentes nos vegetais são muito variáveis e não se distribuem de forma igualitária na planta.

Tabela 1. Efeitos dos distintos períodos de decomposição e diferentes proporções de folhas secas Libidibia ferrea Mart., sobre o desenvolvimento de plântulas de feijão-caupi (Vigna unguiculata L.), cv. Canapu.

\begin{tabular}{cccccc}
\hline $\begin{array}{c}\text { Proporções } \\
(\mathrm{v} / \mathrm{v})\end{array}$ & $\begin{array}{c}\text { CPA } \\
(\mathrm{cm})\end{array}$ & $\begin{array}{c}\text { CSR } \\
(\mathrm{cm})\end{array}$ & $\begin{array}{c}\text { MSPA } \\
(\mathrm{g})\end{array}$ & $\begin{array}{c}\text { MSSR } \\
(\mathrm{g})\end{array}$ & $\begin{array}{c}\text { MST } \\
(\mathrm{g})\end{array}$ \\
\hline $1: 0$ & $3,11 \mathrm{a}$ & $3,06 \mathrm{~b}$ & $1,25 \mathrm{a}$ & $0,47 \mathrm{a}$ & $1,34 \mathrm{a}$ \\
$1: 1 / 2$ & $3,09 \mathrm{a}$ & $3,46 \mathrm{a}$ & $1,13 \mathrm{ab}$ & $0,54 \mathrm{a}$ & $1,25 \mathrm{ab}$ \\
$1: 1$ & $3,15 \mathrm{a}$ & $3,27 \mathrm{ab}$ & $1,12 \mathrm{ab}$ & $0,53 \mathrm{a}$ & $1,23 \mathrm{ab}$ \\
$1: 2$ & $3,08 \mathrm{a}$ & $3,28 \mathrm{ab}$ & $1,04 \mathrm{~b}$ & $0,48 \mathrm{a}$ & $1,14 \mathrm{~b}$ \\
\hline $\mathrm{CV}(\%)$ & 5,47 & 12,88 & 16,52 & 20,67 & 16,37 \\
\hline
\end{tabular}

Médias seguidas pela mesma letra nas colunas não diferem entre si pelo teste de Tukey ao nível de 5\% de probabilidade. CPA Comprimento da parte aérea; CSR - Comprimento do sistema radicular; MSPA - Massa seca da parte aérea; MSSR - Massa seca do sistema radicular e MST - Massa seca total. 


\section{CONCLUSÕES}

O cultivo de feijão-caupi, cv. Canapu, e pau ferro como parte integrante de um sistema agroflorestal, não é viável, pois com 30 dias de decomposição ocorre redução no comprimento da parte aérea e do sistema radicular e massa seca total das plântulas. $\mathrm{O}$ aumento das proporções de folhas secas de pau ferro (Libidibia ferrea Mart.) afeta a massa seca total de plântulas.

\section{REFERÊNCIAS}

CHOU, C. Roles of allelopathy in plant biodiversity and sustainable agriculture. Critical Reviews in Plant Sciences, v.18, n.5, p.609-636. 1999.

CRUZ, S. E. M.; NOZAKI, M. H.; BATISTA, M. A. Plantas medicinais. Biotecnologia Ciência e Desenvolvimento, Brasília, n. 15, p. 28-34, 2000.

FERREIRA, A. G.; BORGHETTI, F. Germinação do básico ao aplicado. 2. ed. Porto Alegre: Artmed, 2004. 323 p.

FERREIRA, D. F. Sisvar: a computer statistical analysis system. Ciência e Agrotecnologia. v.35, n.6, p.1039-1042, 2011.

JANDOVÁ K.; DOSTÁL, P.; CAJTHAML, T. Searching for Heracleum mantegazzianum allelopathy in vitro and in a garden experiment. Biological Invasions, v. 17, n. 4, p. 9871003, 2015. 10.1007/s10530-014-0771-5.

LEWIS, G. P. Libidibia in Lista de Espécies da Flora do Brasil. Jardim Botânico do Rio de Janeiro. Disponível em: <http://floradobrasil.jbrj.gov.br/jabot/floradobrasil/FB109843 >. Acesso em: 10 set. 2018.

LORENZI, H. Árvores Brasileiras: manual de identificação e cultivo de plantas arbóreas nativas do Brasil. Nova Odessa: Plantarum, 2008a. p.126, 384p.

LORENZI, H.; MATOS, F.J.A. Plantas medicinais do Brasil: nativas e exóticas. 2.ed. Nova Odessa, SP: Instituto Plantarum, 2008b. 544p.

MALHEIROS, R. S. P.; SANTANA, F. S.; LINHARES NETO, M. V. L.; MACHADO, L. L.; MAPELI, A. M. Atividade alelopática de extratos de Lafoensia pacari A. ST. -HIL. sobre Lactuca sativa L. e Zea mays L. em condições de laboratório. Revista Brasileira de Agroecologia, v. 9, n. 1, p. 185-194, 2014.

MATOS FILHO, C. H. A.; GOMES, R. L. F.; ROCHA, M.; M.; FREIRE FILHO, F. R.; LOPES, Â. C. A. Potencial produtivo de progênies de feijão-caupi com arquitetura ereta de planta. Ciência Rural, v.39, n.2, p.348-354, 2009.

MINISTÉRIO DO MEIO AMBIENTE (MMA). Biomas Brasileiros Disponível em: <http://www.mma.gov.br/biomas/caatinga > Acesso em: 06 de jan. 2018.
NAKAGAWA, J. Testes de vigor baseados no desempenho de plântulas. In: KRZYZANOWSKI, F. C.; VIEIRA, R. D.; FRANÇA NETO, J. B. (Eds). Vigor de sementes: conceitos e testes. Londrina: ABRATES, p. 1-21. 1999.

NEGI, A.; BATISH, D. R.; SINGH, H. P.; KOHLI, R. K. Allelopathic Effect of Leaves of Invasive tree Broussonetia papyrifera against some crop plants. Annals of Plant Sciences, v. 5, n. 1, p. 1261-1264, 2016. $\underline{10.21746 / \mathrm{aps} .2016 .01 .003}$

OLIVEIRA. A, K.; COELHO, M. F. B.; MAIA, S. S. S.; DIÓGENES, F. E. P. Atividade alelopática de extratos de diferentes orgãos de Caesalpinia ferrea na germinação de alface. Ciência Rural, v.42, n.8, p.1397-1403, 2012.

SANTOS, J. A. S.; TEODORO, P. E.; CORREA, A. M.; SOARES, C. M. G.; RIBEIRO, L. P.; ABREU, H. K. A. Desempenho agronômico e divergência genética entre genótipos de feijão-caupi cultivados no ecótono Cerrado/Pantanal. Bragantia, v. 73, n. 4, p. 377-382, 2014. $\underline{10.1590 / 1678-4499.0250}$

SILVA, J. N., PINTO, M. A. D. S. C. Ação alelopática de folhas secas de umbu, em processo de decomposição, sobre o potencial fisiológico de sementes de feijão caupi. Agrarian Academy, Centro Científico Conhecer - v.4, n.8; 2017.

SOUZA, B. I. F.; ARTIGAS, R. C.; LIMA, E. R. V.; Caatinga e desertificação. Mercator, v.14, n.1, p.131-150, 2015.

VIEIRA, C. L.; FREITAS, A. D.; SILVA, A. F.; SAMPAIO, E. V.; ARAUJO, M. do S. Inoculação de variedades locais de feijão macassar com estirpes selecionados de rizóbio. Revista Brasileira de Engenharia Agrícola e Ambiental, v. 14, n. 11, p. $1170-1175,2010$.

ZHENG, Z.; SHANMUGHAVEL, P., MIN CAO, L. S.; WARREN, M. Litter decomposition and nutrient release in Tropical Seasonal Rain Forest of Xishuangbanna, Southwest China. Biotropica, v. 38, n. 3, p. 342-347, 2006. 